\title{
Epithelial mesenchymal transition and tumor budding in aggressive colorectal cancer: Tumor budding as oncotarget
}

\author{
Inti Zlobec and Alessandro Lugli \\ * Institute for Pathology, University Hospital Basel, Schoenbeinstrasse 40, Basel, Switzerland \\ Correspondence to: Alessandro Lugli, email: alugli@uhbs.ch \\ Keywords: colorectal cancer, tumor budding, epithelial mesenchymal transition, metastasis, oncotarget \\ Received: November 26, 2010, Accepted: November 28, 2010, Published: November 28, 2010
}

Copyright: @ Zlobec et al. This is an open-access article distributed under the terms of the Creative Commons Attribution License, which permits unrestricted use, distribution, and reproduction in any medium, provided the original author and source are credited.

ABSTRACT:

\begin{abstract}
Epithelial mesenchymal transition (EMT) is proposed as a critical mechanism for the acquisition of malignant phenotypes by epithelial cells. In colorectal cancer, tumor cells having undergone EMT are histologically represented by the presence of tumor buds defined as single cells or small clusters of de-differentiated tumor cells at the invasive front. Tumor budding is not a static, histological feature rather it represents a snap-shot of a dynamic process undertaken by an aggressive tumor with the potential to disseminate and metastasize. Strong, consistent evidence shows that tumor budding is a predictor of lymph node metastasis, distant metastatic disease, local recurrence, worse overall and disease-free survival time and an independent prognostic factor. Moreover, the International Union against Cancer (UICC) recognizes tumor budding as a highly relevant, additional prognostic parameter. The aim of this review is to summarize the evidence supporting the implementation of tumor budding into diagnostic pathology and patient management and additionally to illustrate its worthiness as a potential therapeutic target.
\end{abstract}

\section{INTRODUCTION}

Epithelial mesenchymal transition (EMT) is proposed as a critical mechanism for the acquisition of malignant phenotypes by epithelial cells [1]. In colorectal cancer, tumor cells having undergone EMT are histologically represented by the presence of tumor buds defined as single cells or small clusters of dedifferentiated tumor cells at the invasive front [2]. Tumor budding is predictive of lymph node metastasis, vascular and lymphatic invasion, distant metastasis, local recurrence and poor disease-specific survival time [3$15]$ and classified as an "additional" prognostic factor by the International Union against Cancer (UICC) [16]. Despite these highly negative attributes, surprisingly little is known about the events promoting a tumor budding phenotype although in vitro and xenograft animal models of EMT may provide the first clues [17-20]. The aim of this review is to summarize the evidence supporting not only the integration of tumor budding into daily diagnostic pathology and clinical management of colorectal cancer patients but also the targeting of tumor budding as a novel therapeutic approach for patients with this disease.

\section{EPITHELIAL} TRANSITION

MESENCHYMAL

EMT is a biological process allowing a polarized cell, normally interacting with a basement membrane, to assume a mesenchymal phenotype characterized by increased migratory capacity, invasiveness, increased resistance to apoptosis and increased production of extracellular matrix (ECM) components [18]. The completion of EMT is signaled by the degradation of the basement membrane and formation of a mesenchymal cell. Highly relevant for embryogenesis and wound healing, EMT has also been proposed as a critical mechanism for the acquisition of malignant phenotypes by epithelial cells [21]. EMT-derived tumor cells occurring at the invasive tumor front are thought to be those cells entering into subsequent steps of invasion and metastasis. Moreover, these cells have been shown to establish secondary colonies at distant sites that histopathologically resemble the primary tumor of origin through a process known as mesenchymal epithelial transition (MET) [21]. 


\section{HISTOPATHOLOGICAL ASPECTS OF TUMOR BUDDING}

In colorectal cancer, EMT-derived tumor cells are represented histopathologically by the presence of tumor buds and are reported to occur in $20-40 \%$ of tumours $[22,23]$. Occurring predominantly at the invasive front, the identification of tumor buds, defined as single cells or clusters of up to 5 cells can be made using standard H\&E-stained slides or facilitated by using pan-cytokeratin stains (Figure 1) [2]. In addition, these budding cells can often be seen in the company of "pseudo-like" cytoplasmic protrusions in direct contact with adjacent structures which are thought to be a marker of an activated budding phenotype associated with cell motility and increased invasiveness [24]. Histologically, high-grade tumor budding seems to correlate with certain parameters [25], most notably with the infiltrating tumor border configuration defined as widespread dissection of normal tissue structures with loss of a clear boundary between tumor and host tissues [23]. On the other hand, tumor budding occurs significantly less often in tumors with a more "encapsulating" or pushing/expanding growth pattern [26], itself frequently, but not always, accompanied by the presence of dense peritumoral lymphocytic (PTL) inflammation [27].

\section{ACTIVATION OF THE TUMOR BUDDING PHENOTYPE}

The study of EMT and its related signaling pathways could provide the first clues regarding the molecular and genetics events promoting tumor budding in colorectal cancers. EMT-inducing signals from the tumor-associated stroma such as hepatocyte growth factor (HGF), epidermal growth factor (EGF), placental-derived growth factor
(PDGF) and transforming growth factor-beta (TGF-beta) appear to be responsible for the induction or functional activation in cancer cells of a series of EMT-inducing transcription factors such as Snail, Slug, ZEB1, Twist, Goosecoid and FoxC2 [21, 28-31]. Their implementation into the EMT program may depend on a series of intracellular signaling networks involving ERK, MAPK, PI3K, AKT, the SMADs, and integrins [32-34]. The WNT/ Wingless signaling pathway, and its major effectors betacatenin and E-cadherin are however considered integral components of EMT $[21,28]$. Briefly, binding of wnt proteins to a seven-span-transmembrane receptor frizzled (frz) leads to activation of WNT signaling and stabilization of cytoplasmic beta-catenin which can translocate to the cell membrane or nucleus, by mechanisms including regulation of cytokines, matrix metalloproteases (MMPs), TGF-beta, tumor necrosis factor (TNF)-alpha and HGF [35]. Membranous beta-catenin complexes with E-cadherin, a critical mediator of cell-cell adhesion and responsible for the maintenance of cell polarity [22]. In contrast, nuclear beta-catenin can function as an oncogene, binding to Tcf/LEF family members and acting as a transcriptional activator of downstream target genes [36]. Hence, membranous expression of both beta-catenin and E-cadherin characterizes the epithelial phenotype, whereas loss is indicative of a switch toward a more mesenchymal one. Up-regulation of proteins involved in ECM degradation, angiogenesis and migration such as MMP-7, MMP-26, urokinase plasminogen activator receptor (uPAR), vascular endothelial growth factor (VEGF), laminin5y2 -chain, fibronectin and CD44 [22] have all been reported.

\section{IMMUNOHISTOCHEMICAL STUDES}

Immunohistochemical studies have been crucial for improving our understanding of tumor budding (Figure


Figure 1: Tumor budding. Single tumor buds (arrow) at the invasive front of colorectal cancer (H\&E, 40x) (A). The pan-cytokeratin staining better visualizes the number of tumor buds in the same area at the invasive front (CK22, 40x) (B). 
2). High-grade tumor budding is often linked to increased expression of protein markers closely related to ECM degradation such as UPA and UPAR, matrilysin or MMPs as well as those often associated with increased proliferation such as TGF-beta, epidermal growth factor receptor (EGFR), and p53 [37-43]. Markers of cell adhesion and migration such as E-cadherin or syndecan-1 are decreased in the center of tumors with high-grade tumor budding in addition to decreased phospho-AKT, a protein reported to impact cell survival by inhibiting apoptosis [44-46]. Decreased EphB2 and Bcl-2 have been documented [47]. Interestingly, the number of $\mathrm{CD} 8+$ tumor infiltrating lymphocytes (TILs) is markedly decreased in high-grade budders, probably due to the relationship of the immune response with microsatellite instability (MSI) status [46]. Most interesting is the heterogeneity of expression of several markers, predominantly related to cell adhesion, from the tumor centre to the tumor front. Loss of membranous E-cadherin, CD44, CD44v6, EpCAM and CD166 expression have all been reported and often are not expressed within tumor budding cells themselves [48-51]. The finding of loss of these markers associated with more aggressive tumor behavior and high-grade tumor budding may be related to the loss of cell adhesion function which is represented by membranous staining of these markers by immunohistochemistry. Several studies have documented the changes in membranous to more cytoplasmic expression and dual-functions of proteins such as E-cadherin, EpCAM and CD44 with tumor progression, hence caution should therefore be taken to note the intra-cellular localization of these, and possibly other cell adhesion molecules [52-54].

Tumor buds themselves shows a strong and uniform nuclear beta-catenin staining and concomitant loss of membranous E-cadherin expression, in line with what is seen in EMT studies $[21,55,56]$. In addition, overexpression of ECM degradation proteins MMP-2 and MMP-9, uPAR, and laminin5 $\gamma 2$ have all been reported [41, 57-59]. Additional studies have related tumor budding to increased expression of putative stem cell markers

\begin{tabular}{|l|}
\hline \multicolumn{1}{|c|}{ Tumor center } \\
\hline \hline Increased expression: \\
UPA (c), Maspin ( $\mathrm{n})$, pERK ( $\mathrm{n})$, \\
TGF-beta (c), Matrilysin ( $\mathrm{n})$, \\
p53 ( $\mathrm{n})$, UPAR (m/c) \\
\\
Decreased expression: \\
CD8+ T-cells, pAKT (c), \\
syndecan-1 (m) \\
\hline
\end{tabular}

Tumor centre $\rightarrow$ front

Increased expression: $\operatorname{EGFR}(\mathrm{c} / \mathrm{m}), \boldsymbol{\beta}$-catenin ( $\mathrm{n})$, EphB2-/Bcl2- $(\mathrm{c} / \mathrm{m}, \mathrm{c})$

Decreased expression: Ecadherin $(\mathrm{m}), \mathrm{CD} 44(\mathrm{~m})$, CD44v6 (m), CD166 (m), $\operatorname{EpCAM}(m), \operatorname{APAF}-1$ (c)



Tumor buds

Increased expression: MMP-2 (c), MMP-9 (c), CathB (c), CXCL12 (m/c), $\beta$-catenin (n), Beta-IIITubulin (c), hMena (c) Laminin5y2 (c), p16 (c and $n)$, cyclinD1 (n), ABCG5 (c), CD133 (c)

Decreased expression: Ki67 (n), E-cadherin (m)

Figure 2: Overview of different histological features, molecular factors and protein markers linked to high-grade tumor budding. Protein markers have been evaluated in the tumor centre or within tumor budding cells. Additionally, changes in protein expression from the tumor centre to the invasive front have also been related to the presence of tumor budding. Expression described predominantly as $\mathrm{n}=$ nuclear, $\mathrm{m}=$ membranous, or $\mathrm{c}=$ cytoplasmic. Yellow circles represent lymphocytes, in particular CD8+ T-cells. 
CD133 and ABCG5, as well as of beta-III tubulin, a protein involved in migration, CXCL12, a stromal cellderived factor involved in chemotaxis and angiogenesis, hMena, a marker of cell motility and cathepsinB linked to dedifferentiation [57, 60-63]. Interestingly, ABCG5expressing and non-expressing buds have differential effects on patient survival supporting the notion that the level of aggressiveness of tumor buds may depend on their protein profiles [64]. Despite the clear association of tumor budding with migration and invasion, paradoxically, tumor buds seem to undergo low rates of proliferation as evidenced by reduced expression of proliferation marker Ki67 and concomitant increased expression of cell-cycle arrest mediators cyclin D1 and p16 [65, 66].

\section{TUMOR BUDDING MICROSATELLITE INSTABILITY \\ AND}

Whether of sporadic or hereditary origin, tumors with high-level MSI (MSI-H; 15\% of all cases), seem to have very low rates or no tumor budding [67]. In addition, in vitro studies comparing microsatellite stable (MSS) and MSI-H cell lines confirm the reduced EMT in the latter. Several contributing factors may help explain this finding.

\section{Attacker/Defender Model:}

The invasive front of colorectal cancers can be thought of as a dynamic interface of pro- and anti-tumor factors. On the one hand, tumor buds promote progression and dissemination by attempting to penetrate vascular and
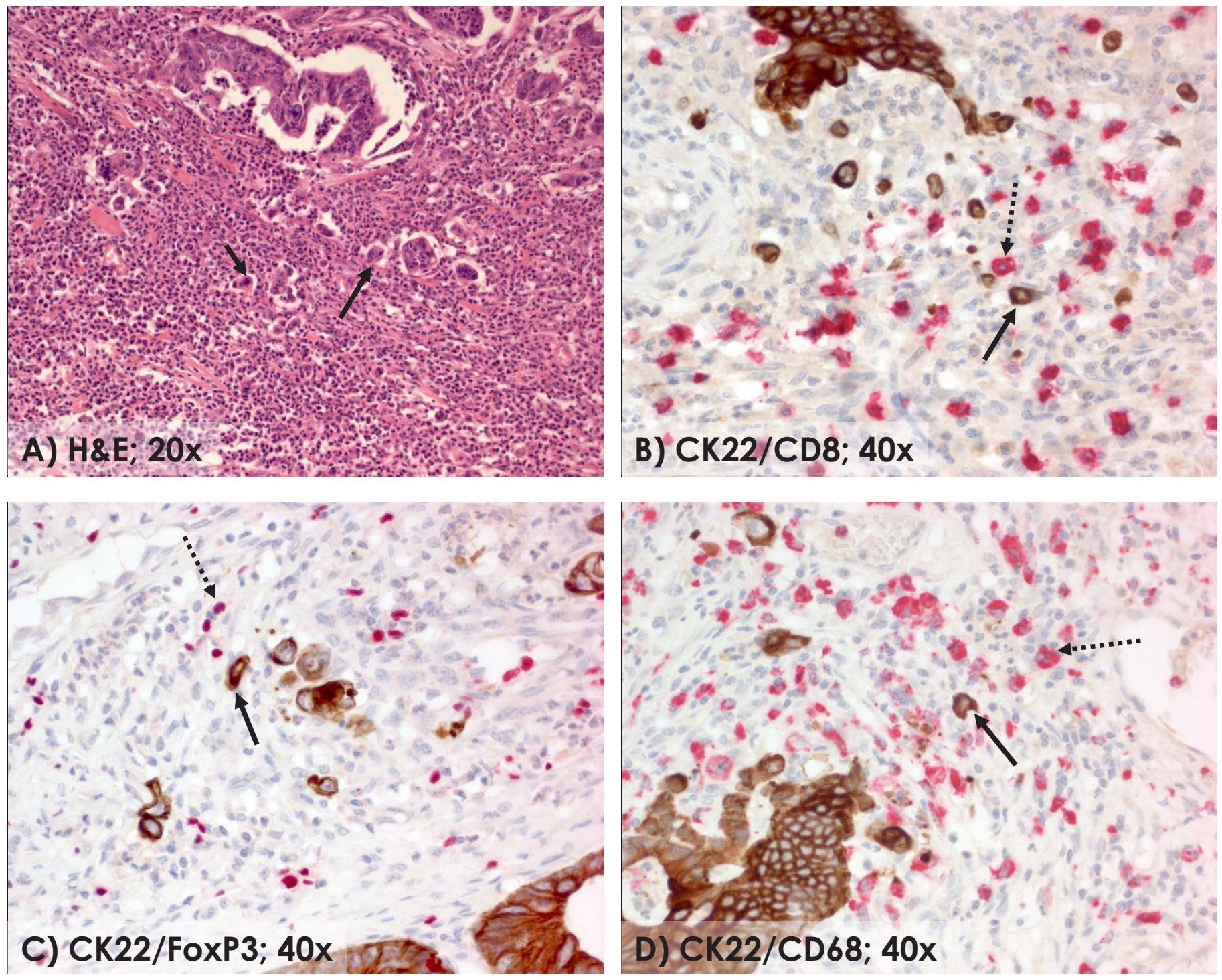

Figure 3: The invasive front of colorectal cancer highlighting the interaction between tumor buds and peritumoral inflammatory cells. (H\&E, 20x) (A). Double staining with CK22 showing presence of inflammatory cells positive for CD8 (B), FoxP3 (C) and CD68 (D) in the microenvironment of tumor buds (40x). Arrows showing examples of tumor buds (solid) and CD8+, FoxP3+ and CD68+ cells (dotted), respectively. 
lymphatic vessels. On the other, the host attempts to fend off this attack by mounting an immune response composed primarily of cytotoxic $\mathrm{T}$ lymphocytes, to protect vascular and lymphatic channels from invasion by tumor buds [68]. MSI-H colorectal cancers exemplify this attacker/defender model and highlight a pro-immunogenic phenotype which may to some extent be responsible for the more favorable prognosis of patients with these forms of colorectal cancers [69]. In comparison to MSS tumors, MSI-H cancers are known to have abundant CD8+ intra-epithelial and stromal TILs [70, 71]. They are most often found with pushing tumor borders accompanied by dense PTL inflammation [71]. It has been previously hypothesized that specific immune responses contained within this PTL infiltrate may be targeting tumor budding cells for destruction, hence their frequent absence at the invasive front in tumors with strong lymphocytic inflammation [46]. We recently investigated the composition of the PTL infiltrate in MSI-H and MSS tumors within the tumor budding microenvironment [72]. Several differences were found including a greater number of CD8+, granzymeB+, CD16+ and CD3+ cells in MSI-H cases. Although the presence of $\mathrm{CD} 8+$ cells among patients with MSI-H tumors does not seem to influence outcome [73], the ratio between $\mathrm{CD} 8+, \mathrm{FOXp3+}$ and $\mathrm{CD} 68+$ cells and the presence of tumor budding has an independent effect on prognosis in both MSS and MSI-H cancers (Figure 3).
Even in cases with no obvious PTL inflammation, the higher the number of CD8+, FOXp3+ and CD68+ cells relative to the number of tumor buds (ratio of immune cells-defenders /tumor budding cells-attackers), the more favorable the impact on patient survival [72]. MSI-H cancers are known to metastasize to a much lesser degree than their MSS counterparts; the abundant immune reaction at the invasive front and particularly within the microenvironment of tumor budding cells may help further to explain this observation.

\section{WNT pathway signaling}

The Wnt signaling pathway, as seen in EMT studies in vitro, is believed to be highly relevant to tumor budding in human colorectal cancer patients. Classically, chromosomally instable (CIN) or MSS but not MSI-H tumors may arise from inactivation of Wnt signaling [67]. Nuclear accumulation of beta-catenin is typically found in MSS colorectal cancers, occurs particularly at the invasive front and within tumor budding cells, and is simultaneously observed in cases with loss of membranous E-cadherin. MSI-H colorectal cancers typically do not show mutations in neither APC, nor present with tumor buds $[67,74]$. The frequency of concomitant APC mutation and tumor budding stratified by MSI status is illustrated in Figure

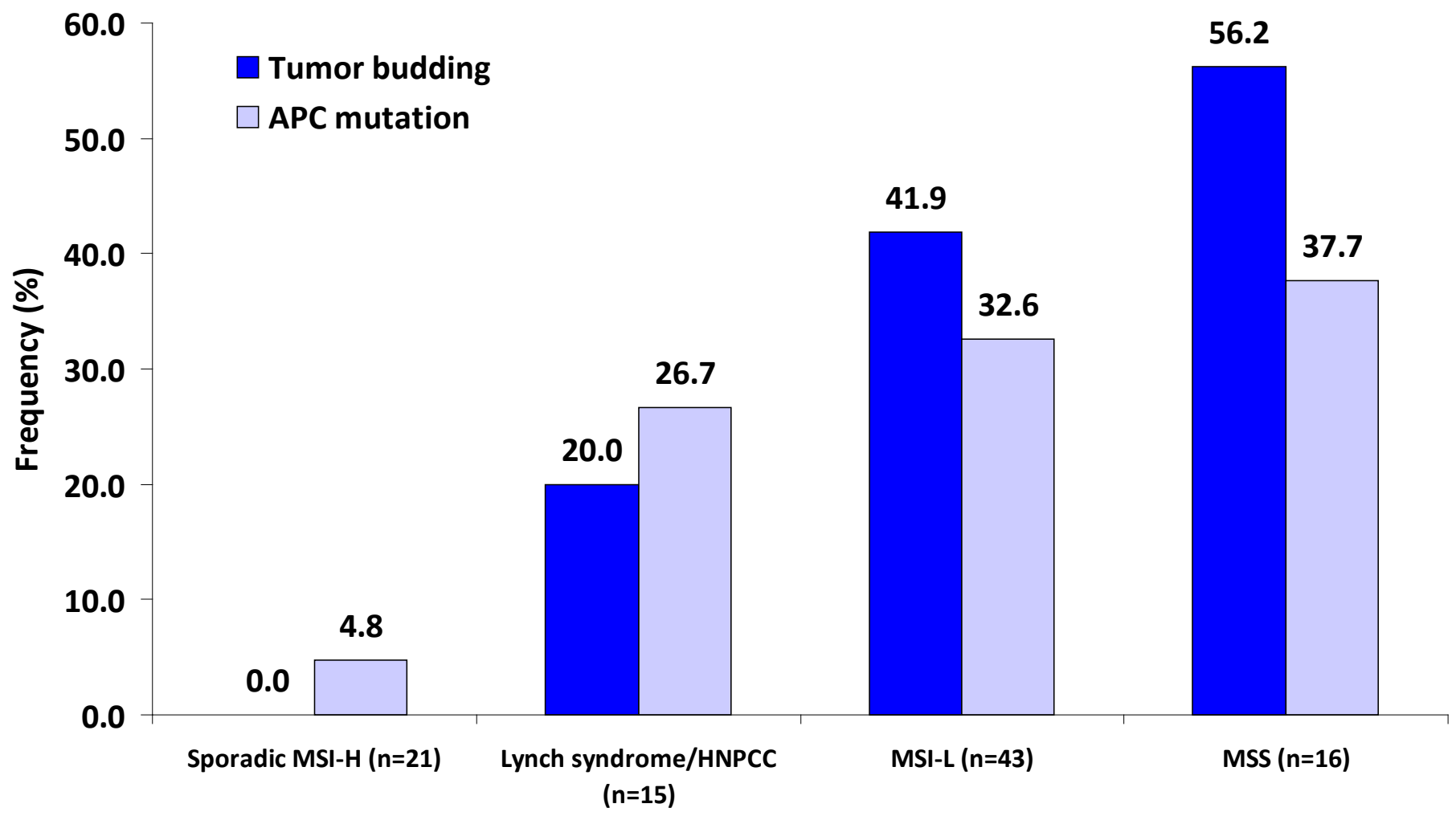

Figure 4: Association between APC mutation and tumor budding stratified by microsatellite instability status (adapted from Jass et al. J Clin Pathol, 2003). Sporadic MSI-H colorectal cancers show the lowest rates of both APC mutation and tumor budding followed by hereditary MSI-H (Lynch syndrome; Hereditary Non-Polyposis Colorectal Cancer) cases, and low-level MSI tumors. Microsatellite stable (MSS) cancers show the greatest rates of tumor budding, accompanied by frequent APC mutation, thus substantiating the relationship between Wnt signaling and this histopathological feature. 
4 [67]. The close relationship between the two features suggests a strong interaction between inactivation of Wnt signaling and the presence of tumor budding.

\section{CpG Island Methylator Phenotype}

MSI-H colorectal cancers have now been linked to high-level CpG Island Methylator Phenotype (CIMP-H), a feature itself strongly related to methylation of CDKN2A (p16) [75]. P16 $6^{\mathrm{INK} 4 \mathrm{~A}}$ is known to be a target gene of betacatenin and often the two proteins are co-expressed within tumor budding cells [76]. Methylation of CDKN2A may lead to gene silencing and consequently decreased levels of nuclear p $16^{\mathrm{INK} 4 \mathrm{a}}$ protein expression [77]. It is therefore expected that tumor budding should be significantly reduced in patients with CIMP-H tumors. Only a handful of studies to date have evaluated CDKN2A methylation in the context of tumor budding. Prall and colleagues found 6 cases of high-grade tumor budding with a complete absence of nuclear $\mathrm{p} 16^{\mathrm{INK} 4 \mathrm{a}}$ protein expression $(10.5 \%)$ and all had concomitant $\mathrm{p} 16^{\mathrm{INK} 4 \mathrm{a}}$ methylation [78]. Eleven methylated cases retained expression of the protein and interestingly, cases with high-grade tumor budding often did not stain for nuclear $\mathrm{p} 16^{\mathrm{INK} 4 \mathrm{a}}$. This lack of concordance between methylation and protein expression has been also described previously [79] and may possibly be explained by the intra-cellular localization of p16. Accumulation of cytoplasmic, rather than nuclear p16 staining has been observed within tumor budding cells [67]. Jass and colleagues hypothesized that the cytoplasmic p16 may bind cdk4 and block its translocation to the nucleus. In the absence of cdk4, cyclinD1 may complex with cdk2 thus limiting the availability of cyclins $\mathrm{A}$ and $\mathrm{E}$ and inhibiting the cell cycle which could explain the low levels of proliferation exhibited by budding cells [67, 80]. Although it has been speculated that this change in intra-cellular localization within tumor buds may be due to promoter methylation of CDKN2A, the role of p16 in tumor budding in both MSS and MSI-H colorectal cancers needs further clarification. In addition, it remains interesting that CIMP-H colorectal cancers, namely those with the lowest predicted amounts of tumor budding seem to be most responsive to chemotherapy [81].

\section{CLINICAL USE OF TUMOR BUDDNIG}

\section{Prognostic and predictive impact of tumor budding}

Tumor budding at the invasive front has been recognized as an adverse parameter and an "additional" prognostic factor by the International Union against Cancer (UICC) [16, 82]. High-grade tumor budding, irrespective of the definition, has been consistently linked to lymph node metastasis [3-8], distant metastasis [9], local recurrence [10-15] and correlates with the distance of tumor invasion beyond the outer border of the muscularis propria [83]. Tumor budding is proposed as a useful indicator of isolated tumor cells in lymph nodes in patients with node-negative colorectal cancers [84] and could indicate additional laparotomy in patients with locally excised T1 tumors $[85,86]$.

The prognostic and independent effect of tumor budding on outcome has been investigated by several study groups. High-grade tumor budding has an independent adverse effect on both overall and diseasefree survival time [23, 84, 87-92] particularly in the presence of cytoplasmic podia [59] and may serve as an additional histopathological parameter to identify stage I or II patients at risk of disease recurrence after curative surgery [93-96]. Even among patients with node-positive or stage III disease, tumor budding has been shown to improve the risk stratification of patients $[4,97]$. However, contradictory findings have been recently reported by Sy and colleagues who found an association of tumor budding with worse outcome in univariate but not multivariate analysis in this subset of patients [98]. Tumor budding may also be a predictive factor in metastatic colorectal cancer patients treated with anti-EGFR therapies [99]. In a retrospective cohort of treated metastatic colorectal cancer patients, high-grade tumor budding could predict non-response to therapy and in combination with KRAS mutational status, predicted response in $80 \%$ of cases. The predictive value of tumor budding to targeted therapy requires further investigation.

In 1989, Morodomi and colleagues published what appears to be the only work evaluating the presence of tumor budding within the tumor centre from pre-operative biopsy specimens [100]. Not only did this type of tumor budding correlate highly with budding at the invasive front, but a clear association between increased numbers of tumor buds in the pre-operative biopsy specimen and lymphatic and lymph node positivity was observed. Further studies are warranted to investigate the potential of this "intra-tumoral" type of budding as a prognostic or predictive factor in the pre-treatment clinical management of colorectal cancer patients.

\section{Scoring systems}

Despite the clear associations of tumor budding with worse clinical outcome and more aggressive tumor parameters, tumor budding has yet to be implemented into daily diagnostic routine. The main reason for this is the absence of standardized scoring systems and sufficient evidence of inter-observer reproducibility for selected evaluation methods.

Two different types of scoring systems have been proposed: subjective and more quantitative/objective. In 1993, Hase and colleagues presented a system based on 
the predominant pattern of tumor budding using a 2-tier method (none or minimal versus moderate or severe) [87]. Nakamura and colleagues, using a similar system, described tumor budding along the entire invasive margin using a 4-tier method (none, mild $<1 / 3$, moderate 1/3-2/3 and severe $>2 / 3$ ) $[9,95]$. More quantitative scoring systems have been reported. The group of Ueno and co-workers proposed 2 methods by counting the number of buds within the field of most dense tumor budding: (1) using a 20x objective lens (area $0.785 \mathrm{~mm} 2$ ) and a cut-off of 5 tumor buds or (2) using a $25 \mathrm{x}$ objective lens (area $0.385 \mathrm{~mm}^{2}$ ) with a cut-off of 10 tumor buds. Inter-observer agreement for the latter was reported at kappa $=0.84$ [23. 101]. Wang and colleagues presented a technique whereby 5 randomly selected areas were evaluated, each given a score based on presence (at least one bud) or absence of tumor budding in each field (area $0.949 \mathrm{~mm}^{2}$ ) and document an interobserver agreement of kappa $=0.75$ [92]. The evaluation of tumor budding cells can be significantly hindered in cases of stromal inflammation or fibrosis at the invasive front. Pan-cytokeratin immunostains facilitate significantly the visualization of tumor buds and are highly recommended for their evaluation [2]. Prall and colleagues scored pancytokeratin-stained tumor buds in a $0.785 \mathrm{~mm}^{2}$ field of vision (250x). Rather than using an arbitrary cut-off score to classify a case as "budding-positive", they used an established statistical cut-point determination method (receiver operating characteristic (ROC) curve analysis) to identify the "optimal" number of tumor buds to be used as a threshold value [96]. Classifying tumors of $\geq 25$ buds/field as positive, they report a strong inter-observer agreement with kappa $=0.874$. Also using ROC curve analysis, our group has shown that with 15 buds/highpower field, the percent concordance between observers was $88 \%(\mathrm{kappa}=0.6)$ [99].

These results show the potential for high-level inter-observer agreement. However, consensus has not been reached yet and international collaborative efforts to standardize scoring of tumor budding are crucial before this feature can be implemented as part of routine diagnostic pathology.

\section{CONCLUSION}

Tumor budding is not a static, histological feature; it represents a snap-shot of a dynamic process undertaken by an aggressive tumor with the potential to disseminate and metastasize. Tumor budding is worth to be therapeutically targeted; the overwhelming and consistent evidence demonstrating that tumor budding is linked to unfavorable tumor-related features, aggressive behavior and worse overall and disease-free survival time suggests that tumor budding should be considered an "essential" prognostic factor along-side $\mathrm{pT}, \mathrm{pN}, \mathrm{pM}$, lymphatic and vascular invasion [16]. As seen in breast and prostate cancers with the BRE and Gleason scores, respectively, tumor budding has the potential to be a basis for a supplementary prognostic scoring system in colorectal cancer once its evaluation has been standardized. The molecular and genetic events triggering a tumor budding phenotype, the changes occurring within tumor budding cells, their interaction with stromal cells and the identification of more or less aggressive tumor budding profiles remain open areas of investigation. Understanding the interactions between tumor buds and the immune response may be key toward the development of future immunotherapy targeting the destruction of tumor budding cells.

\section{CONFLICT OF INTEREST STATEMENT}

The authors have no conflicts of interest.

\section{REFERENCES}

1. Kalluri R, Weinberg RA. The basics of epithelialmesenchymal transition. J Clin Invest 2009;119:1420-8.

2. Prall F. Tumour budding in colorectal carcinoma. Histopathology 2007;50:151-62.

3. Hase K, Shatney $\mathrm{CH}$, Mochizuki H, Johnson DL, Tamakuma S, Vierra M, Trollope M. Long-term results of curative resection of "minimally invasive" colorectal cancer. Dis Colon Rectum 1995;38:19-26.

4. Okuyama T, Oya M, Ishikawa H. Budding as a useful prognostic marker in pT3 well- or moderately-differentiated rectal adenocarcinoma. J Surg Oncol 2003;83:42-7.

5. Sohn DK, Chang HJ, Park JW, Choi DH, Han KS, Hong CW, Jung KH, Kim DY, Lim SB, Choi HS, Jeong SY. Histopathological risk factors for lymph node metastasis in submucosal invasive colorectal carcinoma of pedunculated or semipedunculated type. J Clin Pathol 2007;60:912-5.

6. Tateishi Y, Nakanishi Y, Taniguchi H, Shimoda T, Umemura S. Pathological prognostic factors predicting lymph node metastasis in submucosal invasive (T1) colorectal carcinoma. Mod Pathol;23:1068-72.

7. Wang HS, Liang WY, Lin TC, Chen WS, Jiang JK, Yang SH, Chang SC, Lin JK. Curative resection of T1 colorectal carcinoma: risk of lymph node metastasis and long-term prognosis. Dis Colon Rectum 2005;48:1182-92.

8. Yasuda K, Inomata M, Shiromizu A, Shiraishi N, Higashi H, Kitano S. Risk factors for occult lymph node metastasis of colorectal cancer invading the submucosa and indications for endoscopic mucosal resection. Dis Colon Rectum 2007;50:1370-6.

9. Nakamura T, Mitomi H, Kikuchi S, Ohtani Y, Sato K. Evaluation of the usefulness of tumor budding on the prediction of metastasis to the lung and liver after curative excision of colorectal cancer. Hepatogastroenterology 2005;52:1432-5.

10. Compton CC. Pathologic prognostic factors in the recurrence of rectal cancer. Clin Colorectal Cancer 
$2002 ; 2: 149-60$.

11. Losi L, Ponti G, Gregorio CD, Marino M, Rossi G, Pedroni M, Benatti P, Roncucci L, de Leon MP. Prognostic significance of histological features and biological parameters in stage I (pT1 and pT2) colorectal adenocarcinoma. Pathol Res Pract 2006;202:663-70.

12. Masaki T, Matsuoka H, Sugiyama M, Abe N, Izumisato $Y$, Sakamoto A, Atomi Y. Laminin-5 gamma2 chain expression as a possible determinant of tumor aggressiveness in $\mathrm{T} 1$ colorectal carcinomas. Dig Dis Sci 2003;48:272-8.

13. Okuyama T, Oya M, Yamaguchi M. Budding (sprouting) as a useful prognostic marker in colorectal mucinous carcinoma. Jpn J Clin Oncol 2002;32:412-6.

14. Tanaka M, Hashiguchi Y, Ueno H, Hase K, Mochizuki H. Tumor budding at the invasive margin can predict patients at high risk of recurrence after curative surgery for stage II, T3 colon cancer. Dis Colon Rectum 2003;46:1054-9.

15. Ueno $\mathrm{H}$, Mochizuki $\mathrm{H}$, Hashiguchi $\mathrm{Y}$, Hatsuse $\mathrm{K}$, Fujimoto H, Hase K. Predictors of extrahepatic recurrence after resection of colorectal liver metastases. Br J Surg 2004;91:327-33.

16. Compton C. Prognostic factors in cancer, 3rd ed.ed.: WileyLiss, 2006.

17. Brabletz T, Jung A, Spaderna S, Hlubek F, Kirchner T. Opinion: migrating cancer stem cells - an integrated concept of malignant tumour progression. Nat Rev Cancer 2005;5:744-9.

18. Kalluri R. EMT: when epithelial cells decide to become mesenchymal-like cells. J Clin Invest 2009;119:1417-9.

19. Moreno-Bueno G, Cubillo E, Sarrio D, Peinado H, Rodriguez-Pinilla SM, Villa S, Bolos V, Jorda M, Fabra A, Portillo F, Palacios J, Cano A. Genetic profiling of epithelial cells expressing E-cadherin repressors reveals a distinct role for Snail, Slug, and E47 factors in epithelialmesenchymal transition. Cancer Res 2006;66:9543-56.

20. Moreno-Bueno G, Peinado H, Molina P, Olmeda D, Cubillo E, Santos V, Palacios J, Portillo F, Cano A. The morphological and molecular features of the epithelial-tomesenchymal transition. Nat Protoc 2009;4:1591-613.

21. Brabletz T, Hlubek F, Spaderna S, Schmalhofer O, Hiendlmeyer E, Jung A, Kirchner T. Invasion and metastasis in colorectal cancer: epithelial-mesenchymal transition, mesenchymal-epithelial transition, stem cells and beta-catenin. Cells Tissues Organs 2005;179:56-65.

22. Guarino M, Rubino B, Ballabio G. The role of epithelialmesenchymal transition in cancer pathology. Pathology 2007;39:305-18.

23. Ueno H, Murphy J, Jass JR, Mochizuki H, Talbot IC. Tumour 'budding' as an index to estimate the potential of aggressiveness in rectal cancer. Histopathology 2002;40:127-32.

24. Shinto E, Mochizuki H, Ueno H, Matsubara O, Jass JR. A novel classification of tumour budding in colorectal cancer based on the presence of cytoplasmic pseudo-fragments around budding foci. Histopathology 2005;47:25-31.

25. Jass J. Tumor budding in colorectal cancer, Chapter 5ed. New York: Nova Science Publishers, 2006.

26. Jass JR, Atkin WS, Cuzick J, Bussey HJ, Morson BC, Northover JM, Todd IP. The grading of rectal cancer: historical perspectives and a multivariate analysis of 447 cases. Histopathology 1986;10:437-59.

27. Jass JR. Lymphocytic infiltration and survival in rectal cancer. J Clin Pathol 1986;39:585-9.

28. Brabletz T, Jung A, Reu S, Porzner M, Hlubek F, KunzSchughart LA, Knuechel R, Kirchner T. Variable betacatenin expression in colorectal cancers indicates tumor progression driven by the tumor environment. Proc Natl Acad Sci U S A 2001;98:10356-61.

29. Larriba MJ, Casado-Vela J, Pendas-Franco N, Pena R, Garcia de Herreros A, Berciano MT, Lafarga M, Casal JI, Munoz A. Novel snaill target proteins in human colon cancer identified by proteomic analysis. PLoS One;5:e10221.

30. Roger L, Jullien L, Gire V, Roux P. Gain of oncogenic function of p53 mutants regulates E-cadherin expression uncoupled from cell invasion in colon cancer cells. J Cell Sci;123:1295-305.

31. Sanchez-Tillo E, Lazaro A, Torrent R, Cuatrecasas M, Vaquero EC, Castells A, Engel P, Postigo A. ZEB1 represses E-cadherin and induces an EMT by recruiting the SWI/SNF chromatin-remodeling protein BRG1. Oncogene;29:3490-500.

32. Brabletz S, Schmalhofer O, Brabletz T. Gastrointestinal stem cells in development and cancer. J Pathol 2009;217:307-17.

33. Kim S, Kang HY, Nam EH, Choi MS, Zhao XF, Hong CS, Lee JW, Lee JH, Park YK. TMPRSS4 induces invasion and epithelial-mesenchymal transition through upregulation of integrin alpha5 and its signaling pathways. Carcinogenesis;31:597-606.

34. Pelaez IM, Kalogeropoulou M, Ferraro A, Voulgari A, Pankotai T, Boros I, Pintzas A. Oncogenic RAS alters the global and gene-specific histone modification pattern during epithelial-mesenchymal transition in colorectal carcinoma cells. Int J Biochem Cell Biol;42:911-20.

35. Bates RC, Pursell BM, Mercurio AM. Epithelialmesenchymal transition and colorectal cancer: gaining insights into tumor progression using LIM 1863 cells. Cells Tissues Organs 2007;185:29-39.

36. Katoh M, Katoh M. Cross-talk of WNT and FGF signaling pathways at GSK3beta to regulate beta-catenin and SNAIL signaling cascades. Cancer Biol Ther 2006;5:1059-64.

37. Ceccarelli C, Piazzi G, Paterini P, Pantaleo MA, Taffurelli M, Santini D, Martinelli GN, Biasco G. Concurrent EGFr and Cox-2 expression in colorectal cancer: proliferation impact and tumour spreading. Ann Oncol 2005;16 Suppl 4:iv74-79.

38. Guzinska-Ustymowicz K, Kemona A. Transforming growth factor beta can be a parameter of aggressiveness of $\mathrm{pT} 1$ 
colorectal cancer. World J Gastroenterol 2005;11:1193-5.

39. Ljuslinder I, Melin B, Henriksson ML, Oberg A, Palmqvist R. Increased epidermal growth factor receptor expression at the invasive margin is a negative prognostic factor in colorectal cancer. Int J Cancer 2010.

40. Markl B, Renk I, Oruzio DV, Jahnig H, Schenkirsch G, Scholer C, Ehret W, Arnholdt HM, Anthuber M, Spatz $\mathrm{H}$. Tumour budding, uPA and PAI-1 are associated with aggressive behaviour in colon cancer. J Surg Oncol 2010;102:235-41.

41. Masaki T, Sugiyama M, Matsuoka H, Abe N, Izumisato Y, Sakamoto A, Atomi Y. Coexpression of matrilysin and laminin-5 gamma2 chain may contribute to tumor cell migration in colorectal carcinomas. Dig Dis Sci 2003;48:1262-7.

42. Minoo P, Baker K, Baumhoer D, Terracciano L, Lugli A, Zlobec I. Urokinase-type plasminogen activator is a marker of aggressive phenotype and an independent prognostic factor in mismatch repair-proficient colorectal cancer. Hum Pathol 2009.

43. Pyke C, Salo S, Ralfkiaer E, Romer J, Dano K, Tryggvason $\mathrm{K}$. Laminin-5 is a marker of invading cancer cells in some human carcinomas and is coexpressed with the receptor for urokinase plasminogen activator in budding cancer cells in colon adenocarcinomas. Cancer Res 1995;55:4132-9.

44. Fujiya M, Watari J, Ashida T, Honda M, Tanabe H, Fujiki T, Saitoh Y, Kohgo Y. Reduced expression of syndecan-1 affects metastatic potential and clinical outcome in patients with colorectal cancer. Jpn J Cancer Res 2001;92:1074-81.

45. Lugli A, Zlobec I, Minoo P, Baker K, Tornillo L, Terracciano L, Jass JR. Role of the mitogen-activated protein kinase and phosphoinositide 3-kinase/AKT pathways downstream molecules, phosphorylated extracellular signalregulated kinase, and phosphorylated AKT in colorectal cancer-a tissue microarray-based approach. Hum Pathol 2006;37:1022-31.

46. Zlobec I, Lugli A, Baker K, Roth S, Minoo P, Hayashi S, Terracciano L, Jass JR. Role of APAF-1, E-cadherin and peritumoral lymphocytic infiltration in tumour budding in colorectal cancer. J Pathol 2007;212:260-8.

47. Karamitopoulou E, Lugli A, Panayiotides I, Karakitsos P, Peros G, Rallis G, Patsouris ES, Terracciano L, Zlobec I. Systematic assessment of protein phenotypes characterizing high-grade tumour budding in mismatch repair-proficient colorectal cancer. Histopathology 2010;57:233-43.

48. Coppola D, Hyacinthe M, Fu L, Cantor AB, Karl R, Marcet J, Cooper DL, Nicosia SV, Cooper HS. CD44V6 expression in human colorectal carcinoma. Hum Pathol 1998;29:62735.

49. Gosens MJ, van Kempen LC, van de Velde CJ, van Krieken JH, Nagtegaal ID. Loss of membranous Ep-CAM in budding colorectal carcinoma cells. Mod Pathol 2007;20:221-32.

50. Nanashima A, Yamaguchi $H$, Sawai $T$, Yasutake T, Tsuji T, Jibiki M, Yamaguchi E, Nakagoe T, Ayabe H.
Expression of adhesion molecules in hepatic metastases of colorectal carcinoma: relationship to primary tumours and prognosis after hepatic resection. J Gastroenterol Hepatol 1999;14:1004-9.

51. Zlobec I, Gunthert U, Tornillo L, Iezzi G, Baumhoer D, Terracciano L, Lugli A. Systematic assessment of the prognostic impact of membranous CD44v6 protein expression in colorectal cancer. Histopathology 2009;55:564-75.

52. Ponta H, Sherman L, Herrlich PA. CD44: from adhesion molecules to signalling regulators. Nat Rev Mol Cell Biol 2003;4:33-45.

53. Trzpis M, McLaughlin PM, de Leij LM, Harmsen MC. Epithelial cell adhesion molecule: more than a carcinoma marker and adhesion molecule. Am J Pathol 2007;171:38695.

54. Vessey CJ, Wilding J, Folarin N, Hirano S, Takeichi M, Soutter P, Stamp GW, Pignatelli M. Altered expression and function of E-cadherin in cervical intraepithelial neoplasia and invasive squamous cell carcinoma. J Pathol 1995;176:151-9.

55. Brabletz T. Tumor Budding in Colorectal Cancer; Chapter 4ed. New York: Nova Science Publishers, Inc., 2006.

56. Horkko TT, Klintrup K, Makinen JM, Napankangas JB, Tuominen HJ, Makela J, Karttunen TJ, Makinen MJ. Budding invasive margin and prognosis in colorectal cancer--no direct association with beta-catenin expression. Eur J Cancer 2006;42:964-71.

57. Guzinska-Ustymowicz K. MMP-9 and cathepsin B expression in tumor budding as an indicator of a more aggressive phenotype of colorectal cancer (CRC). Anticancer Res 2006;26:1589-94.

58. Masaki T, Goto A, Sugiyama M, Matsuoka H, Abe N, Sakamoto A, Atomi Y. Possible contribution of CD44 variant 6 and nuclear beta-catenin expression to the formation of budding tumor cells in patients with $\mathrm{T} 1$ colorectal carcinoma. Cancer 2001;92:2539-46.

59. Shinto E, Jass JR, Tsuda H, Sato T, Ueno H, Hase K, Mochizuki H, Matsubara O. Differential prognostic significance of morphologic invasive markers in colorectal cancer: tumor budding and cytoplasmic podia. Dis Colon Rectum 2006;49:1422-30.

60. Akishima-Fukasawa Y, Nakanishi Y, Ino Y, Moriya Y, Kanai Y, Hirohashi S. Prognostic significance of CXCL12 expression in patients with colorectal carcinoma. Am J Clin Pathol 2009;132:202-10; quiz 307.

61. Li CY, Li BX, Liang Y, Peng RQ, Ding Y, Xu DZ, Zhang X, Pan ZZ, Wan DS, Zeng YX, Zhu XF, Zhang XS. Higher percentage of CD133+ cells is associated with poor prognosis in colon carcinoma patients with stage IIIB. J Transl Med 2009;7:56.

62. Portyanko A, Kovalev P, Gorgun J, Cherstvoy E. beta(III)tubulin at the invasive margin of colorectal cancer: possible link to invasion. Virchows Arch 2009;454:541-8. 
63. Toyoda A, Kawana H, Azuhata K, Yu J, Omata A, Kishi $\mathrm{H}$, Higashi M, Harigaya K. Aberrant expression of human ortholog of mammalian enabled (hMena) in human colorectal carcinomas: implications for its role in tumor progression. Int J Oncol 2009;34:53-60.

64. Hostettler L, Zlobec I, Terracciano L, Lugli A. ABCG5positivity in tumor buds is an indicator of poor prognosis in node-negative colorectal cancer patients. World J Gastroenterol 2010;16:732-9.

65. Jung A, Schrauder M, Oswald U, Knoll C, Sellberg P, Palmqvist R, Niedobitek G, Brabletz T, Kirchner T. The invasion front of human colorectal adenocarcinomas shows co-localization of nuclear beta-catenin, cyclin D1, and p16INK4A and is a region of low proliferation. Am J Pathol 2001;159:1613-7.

66. Rubio CA. Arrest of cell proliferation in budding tumor cells ahead of the invading edge of colonic carcinomas. A preliminary report. Anticancer Res 2008;28:2417-20.

67. Jass JR, Barker M, Fraser L, Walsh MD, Whitehall VL, Gabrielli B, Young J, Leggett BA. APC mutation and tumour budding in colorectal cancer. J Clin Pathol 2003;56:69-73.

68. Zlobec I, Lugli A. Invasive front of colorectal cancer: dynamic interface of pro-/anti-tumor factors. World $\mathrm{J}$ Gastroenterol 2009;15:5898-906.

69. Popat S, Hubner R, Houlston RS. Systematic review of microsatellite instability and colorectal cancer prognosis. J Clin Oncol 2005;23:609-18.

70. Jass JR, Do KA, Simms LA, Iino H, Wynter C, Pillay SP, Searle J, Radford-Smith G, Young J, Leggett B. Morphology of sporadic colorectal cancer with DNA replication errors. Gut 1998;42:673-9.

71. Jenkins MA, Hayashi S, O'Shea AM, Burgart LJ, Smyrk TC, Shimizu D, Waring PM, Ruszkiewicz AR, Pollett AF, Redston M, Barker MA, Baron JA, et al. Pathology features in Bethesda guidelines predict colorectal cancer microsatellite instability: a population-based study. Gastroenterology 2007;133:48-56.

72. Zlobec I, Minoo P, Terracciano L, Baker K, Lugli A. Characterization of the immunological microenvironment of tumour buds and its impact on prognosis in mismatch repair-proficient and-deficient colorectal cancers. Histopathology In press.

73. Baker K, Zlobec I, Tornillo L, Terracciano L, Jass JR, Lugli A. Differential significance of tumour infiltrating lymphocytes in sporadic mismatch repair deficient versus proficient colorectal cancers: a potential role for dysregulation of the transforming growth factor-beta pathway. Eur J Cancer 2007;43:624-31.

74. Pino MS, Kikuchi H, Zeng M, Herraiz MT, Sperduti I, Berger D, Park DY, Iafrate AJ, Zukerberg LR, Chung DC. Epithelial to Mesenchymal Transition Is Impaired in Colon Cancer Cells With Microsatellite Instability. Gastroenterology 2009.
75. Shima K, Nosho K, Baba Y, Cantor M, Meyerhardt JA, Giovannucci EL, Fuchs CS, Ogino S. Prognostic significance of CDKN2A (p16) promoter methylation and loss of expression in 902 colorectal cancers: Cohort study and literature review. Int J Cancer 2010.

76. Mann B, Gelos M, Siedow A, Hanski ML, Gratchev A, Ilyas M, Bodmer WF, Moyer MP, Riecken EO, Buhr HJ, Hanski C. Target genes of beta-catenin-T cell-factor/ lymphoid-enhancer-factor signaling in human colorectal carcinomas. Proc Natl Acad Sci U S A 1999;96:1603-8.

77. Toyota M, Ahuja N, Ohe-Toyota M, Herman JG, Baylin $\mathrm{SB}$, Issa JP. CpG island methylator phenotype in colorectal cancer. Proc Natl Acad Sci U S A 1999;96:8681-6.

78. Prall F, Ostwald C, Weirich V, Nizze H. p16(INK4a) promoter methylation and 9p21 allelic loss in colorectal carcinomas: relation with immunohistochemical p16(INK4a) expression and with tumor budding. Hum Pathol 2006;37:578-85.

79. Schneider-Stock R, Boltze C, Peters B, Hopfner T, Meyer F, Lippert H, Roessner A. Differences in loss of p16INK4 protein expression by promoter methylation between leftand right-sided primary colorectal carcinomas. Int J Oncol 2003;23:1009-13.

80. Sweeney KJ, Sarcevic B, Sutherland RL, Musgrove EA. Cyclin D2 activates Cdk2 in preference to Cdk4 in human breast epithelial cells. Oncogene 1997;14:1329-40.

81. Van Rijnsoever M, Elsaleh H, Joseph D, McCaul K, Iacopetta B. $\mathrm{CpG}$ island methylator phenotype is an independent predictor of survival benefit from 5-fluorouracil in stage III colorectal cancer. Clin Cancer Res 2003;9:2898-903.

82. Turner RR, Li C, Compton CC. Newer pathologic assessment techniques for colorectal carcinoma. Clin Cancer Res 2007;13:6871s-6s.

83. Yoshida K, Yoshimatsu K, Otani T, Yokomizo H, Ogawa $\mathrm{K}$. The depth of tumor invasion beyond the outer border of the muscularis propria as a prognostic factor for T3 rectal/ rectosigmoid cancer. Anticancer Res 2008;28:1773-8.

84. Park KJ, Choi HJ, Roh MS, Kwon HC, Kim C. Intensity of tumor budding and its prognostic implications in invasive colon carcinoma. Dis Colon Rectum 2005;48:1597-602.

85. Masaki T, Matsuoka H, Sugiyama M, Abe N, Sakamoto A, Atomi Y. Actual number of tumor budding as a new tool for the individualization of treatment of T1 colorectal carcinomas. J Gastroenterol Hepatol 2006;21:1115-21.

86. Ueno H, Hashiguchi Y, Kajiwara Y, Shinto E, Shimazaki H, Kurihara H, Mochizuki H, Hase K. Proposed objective criteria for «grade $3 »$ in early invasive colorectal cancer. Am J Clin Pathol;134:312-22.

87. Hase K, Shatney C, Johnson D, Trollope M, Vierra M. Prognostic value of tumor «budding» in patients with colorectal cancer. Dis Colon Rectum 1993;36:627-35.

88. Kanazawa H, Mitomi H, Nishiyama Y, Kishimoto I, Fukui N, Nakamura T, Watanabe M. Tumour budding at invasive margins and outcome in colorectal cancer. Colorectal Dis 
2008;10:41-7.

89. Nilsson PJ, Rubio C, Lenander C, Auer G, Glimelius B. Tumour budding detected by laminin-5 \{gamma\}2-chain immunohistochemistry is of prognostic value in epidermoid anal cancer. Ann Oncol 2005;16:893-8.

90. Ohtsuki K, Koyama F, Tamura T, Enomoto Y, Fujii H, Mukogawa T, Nakagawa T, Uchimoto K, Nakamura S, Nonomura A, Nakajima Y. Prognostic value of immunohistochemical analysis of tumor budding in colorectal carcinoma. Anticancer Res 2008;28:1831-6.

91. Ueno H, Price AB, Wilkinson KH, Jass JR, Mochizuki $\mathrm{H}$, Talbot IC. A new prognostic staging system for rectal cancer. Ann Surg 2004;240:832-9.

92. Wang LM, Kevans D, Mulcahy H, O>Sullivan J, Fennelly D, Hyland J, O〉Donoghue D, Sheahan K. Tumor budding is a strong and reproducible prognostic marker in T3N0 colorectal cancer. Am J Surg Pathol 2009;33:134-41.

93. Masaki T, Matsuoka H, Sugiyama M, Abe N, Goto A, Sakamoto A, Atomi Y. Matrilysin (MMP-7) as a significant determinant of malignant potential of early invasive colorectal carcinomas. Br J Cancer 2001;84:1317-21.

94. Masaki T, Matsuoka H, Sugiyama M, Abe N, Sakamoto A, Watanabe T, Nagawa H, Atomi Y. Tumor budding and evidence-based treatment of T2 rectal carcinomas. J Surg Oncol 2005;92:59-63.

95. Nakamura T, Mitomi H, Kanazawa H, Ohkura Y, Watanabe M. Tumor budding as an index to identify high-risk patients with stage II colon cancer. Dis Colon Rectum 2008;51:56872.

96. Prall F, Nizze H, Barten M. Tumour budding as prognostic factor in stage I/II colorectal carcinoma. Histopathology 2005;47:17-24.

97. Choi HJ, Park KJ, Shin JS, Roh MS, Kwon HC, Lee HS. Tumor budding as a prognostic marker in stage-III rectal carcinoma. Int J Colorectal Dis 2007;22:863-8.

98. Sy J, Fung CL, Dent OF, Chapuis PH, Bokey L, Chan C. Tumor budding and survival after potentially curative resection of node-positive colon cancer. Dis Colon Rectum;53:301-7.

99. Zlobec I, Molinari F, Martin V, Mazzucchelli L, Saletti P, Trezzi R, Dosso SD, Vlajnic T, Frattini M, Lugli A. Tumor budding predicts response to anti-EGFR therapies in metastatic colorectal cancer patients. World J Gastroenterol 2010;16:4823-31.

100. Morodomi T, Isomoto H, Shirouzu K, Kakegawa K, Irie $\mathrm{K}$, Morimatsu M. An index for estimating the probability of lymph node metastasis in rectal cancers. Lymph node metastasis and the histopathology of actively invasive regions of cancer. Cancer 1989;63:539-43.

101. Ueno H, Mochizuki H, Hashiguchi Y, Shimazaki H, Aida S, Hase K, Matsukuma S, Kanai T, Kurihara H, Ozawa K, Yoshimura K, Bekku S. Risk factors for an adverse outcome in early invasive colorectal carcinoma. Gastroenterology 2004;127:385-94. 